\title{
Classical conditioning of model systems: A behavioral review
}

\author{
BERNARD G. SCHREURS \\ National Institutes of Health, Bethesda, Maryland
}

\begin{abstract}
The present review examines briefly the history and status of classical conditioning as a means of studying associative learning and assesses the ability of a cross section of model systems to demonstrate associative learning when classical conditioning procedures are employed. It is suggested that model systems that show the emergence of a new (i.e. conditioned) response as a result of being subjected to classical conditioning procedures have unequivocally demonstrated associative learning. In contrast, the ability of model systems to demonstrate associative learning when classical conditioning procedures result in a pairing-specific change in an existing response depends on how associative learning is defined. The advantages of a traditional definition of associative learning for uncovering the neural substrates of learning are discussed.
\end{abstract}

To study the neural substrates of learning, neuroscientists have sought to adopt model systems, preparations that have unequivocally demonstrated learning and are tractable to neural analysis. Traditionally, invertebrate preparations have been utilized to study the neural basis of single-stimulus learning (e.g., habituation: Pinsker, Kupfermann, Castellucci, \& Kandel, 1970; Wine, Krasne, \& Chen, 1975; Zucker, 1972; and sensitization: Bullock, 1948; Castellucci \& Kandel, 1976; Kandel \& Schwartz, 1982), and vertebrate preparations have been employed to examine the substrates of associative learning (e.g., Cegavske, Thompson, Patterson, \& Gormezano, 1976; Cohen, 1969, 1980; Gabriel, Foster, Orona, Saltwick, \& Stanton, 1980; Patterson, 1976; Woody, 1982). Researchers have also employed invertebrate preparations when trying to determine the neural locus of associative learning (e.g., Alkon, 1974, 1976, 1987; Carew, Walters, \& Kandel, 1981; Mpitsos, Collins, \& McClellan, 1978; Sahley, Gelperin, \& Rudy, 1981; for a history of early invertebrate research, see Corning, Dyal, \& Willows, 1973).

Despite the growing body of research employing both vertebrate and invertebrate preparations as model systems, it remains unclear whether all the vertebrate and invertebrate preparations being subjected to classical conditioning procedures demonstrate associative learning. The purpose of the present review is fourfold: (1) to examine briefly the history and status of classical conditioning as a means of demonstrating associative learning; (2) to assess the ability of a cross section of model systems to

Work on this manuscript was supported, in part, by NSF Grant BNS84 19772 to Professor I. Gormezano. The author would like to thank D. L. Alkon, I. Gormezano, E. J. Kehoe, I. I. Lederhendler, J. LoTurco, and L. D. Matzel for helpful comments on earlier drafts of the manuscript. Correspondence may be sent to Bernard G. Schreurs, Section on Neural Systems, NINDS, Park 5 Building, Room 431, National Institutes of Health, Bethesda, MD 20892. demonstrate associative learning when subjected to classical conditioning procedures; (3) to examine whether a pairing-specific change in an existing response is sufficient evidence for associative learning when classical conditioning procedures are employed; and (4) to explore the relative merits of "modern" versus "traditional" definitions of associative learning procedures for uncovering the neural substrates of associative learning.

\section{ASSOCIATIVE LEARNING}

Associative learning may be defined as a relatively permanent change in behavior that results from the temporal conjunction of two events (e.g., Gormezano, 1984; Hilgard \& Marquis, 1940; Kimble, 1961). Despite a number of important caveats, such as "behaviorally silent" learning (e.g., Dickinson, 1980; Mackintosh, 1983; Pearce \& Hall, 1980; Rescorla, 1978), the definition of associative learning, as stated, continues to be of heuristic value. It seems clear, however, that not every two events that occur together are associated. Aristotle proposed that previous contiguity, as well as similarity and contrast, determined which events would be recalled together. Subsequently, the British Empiricists postulated the laws of association as a means of formally specifying which events would become associated. The law of contiguity stated that an associative connection between two events would be formed only if they occurred in spatial and temporal proximity to one another. Secondary laws of association dealt with the frequency with which events occurred in contiguity, the duration of events, their intensities, the number of other associations in which the two events had been involved, the similarity of the association to other associations, and the abilities, emotional state, and bodily state of the person experiencing the events (Brown, 1820/1977; see Gormezano \& Kehoe, 1981).

The first empirical assessment of the laws of association was conducted by Ebbinghaus (1913), who documented 
his own ability to learn and then relearn pairs of nonsense syllables. However, the study of associations received its major impetus from Bekhterev (1913), who proposed classical conditioning as a prototypical example of associative learning (Hilgard \& Marquis, 1940). In the United States, Lashley (1916, p. 459) identified the classical conditioning procedure and the resulting formation of a conditioned response to an originally indifferent stimulus as an "almost ideal example" of associative learning (Gormezano \& Kehoe, 1981). Just 5 years later, S. Smith and Guthrie (1921) abandoned the notion of classical conditioning as merely an example of associative learning and claimed that classical conditioning was synonymous with associative learning (Gormezano \& Kehoe, 1981; Hilgard \& Marquis, 1940).

\section{CLASSICAL CONDITIONING}

\section{Defining Characteristics}

The proposal that classical conditioning was synonymous with associative learning (S. Smith \& Guthrie, 1921) and the ensuing use of classical conditioning as a means of studying associative learning (Hull, 1934; cf. Rescorla, $1988 \mathrm{~b})$ necessitated the identification of classical conditioning's defining characteristics and the specification of its appropriate control procedures (e.g., Gormezano, 1966; Hull, 1934; Hilgard \& Marquis, 1940; Kimble, 1961). A recent restatement of the defining characteristics of classical conditioning includes: (1) the presentation of an unconditioned stimulus (UCS) that reliably elicits an unconditioned response (UCR); (2) the use of a conditioned stimulus (CS) that has been shown by test not initially to produce a response resembling the UCR; (3) the repeated presentation of the CS and UCS to the organism in a specified order and temporal spacing; and (4) the emergence of a response to the CS, the conditioned response (CR), which is similar to the UCR (Flaherty, 1985; Gormezano, 1984; but see Skinner, 1938).

In the last 20 years, a more contemporary, or modern (Rescorla, 1988b), conceptualization of classical conditioning has emerged that has been characterized as the study of the relations among stimuli in the environment (e.g., Dickinson, 1980; Mackintosh, 1983; Rescorla, $1968,1988 \mathrm{a}, 1988 \mathrm{~b})$. In a modern description of classical conditioning, the CS is said to signal the UCS, and the question is whether exposure to the relation between the CS and UCS modifies the organism in a detectable way (e.g., Rescorla, 1988a). If an organism shows an augmented response to the $\mathrm{CS}$ as a result of being exposed to the relationship between the CS and UCS, an association is said to have been formed between the two events (e.g., Rescorla, 1988a).

\section{Control Procedures}

The need to specify appropriate control procedures acknowledges the fact that, although repeated pairings of a CS and UCS may, under appropriate conditions, lead to the emergence of a conditioned response, the occur- rence of a response to the CS may result from nonassociative, as well as associative, processes. The first of the nonassociative factors that may influence responding is the baseline level of activity that occurs in most response systems. The second factor is the elicitation by the CS of unconditioned responding in the target response system and/or in other response systems. For example, a bright light can elicit a reflexive blink in many species, including humans. A bright light may also produce changes in heart rate, respiration, and the galvanic skin response. If the eyeblink is the target response, the occurrence of a reflexive or unconditioned blink to the light has been termed an alpha response (e.g., Grant, 1944), and changes in the reflexive blink as a result of CS-UCS pairings has been termed alpha conditioning (Carew, Abrams, Hawkins, \& Kandel, 1984; Grant \& Adams, 1944; Hull, 1934; Kandel \& Spencer, 1968) If the change in heart rate is the target response, then the reflexive blink to light is a response to the $\mathrm{CS}$ in an effector system other than that containing the target response. The third potential nonassociative contributor to responding is the sensitizing effect presentation that a UCS may have on the frequency of baseline responding and/or CS-elicited responses. To assess the contribution of nonassociative processes to responding, researchers have adopted control procedures incorporating UCS alone, CS alone, and explicitly unpaired presentations of the CS and UCS (see Gormezano \& Kehoe, 1975).

An alternative approach to control procedures, epitomized by the "truly random" control (Rescorla, 1967), is based on manipulating the degree to which there is a relationship between the CS and UCS. For example, in the explicitly unpaired control procedure, the CS and UCS never occur together; thus, there is a negative relationship between the CS and UCS. In fact, the CS is thought of as a perfect predictor of the absence of the UCS (Rescorla, 1967). Conversely, the truly random control procedure consists of independently programmed occurrences of the CS and UCS, which are presented in an attempt to ensure that there is no consistent relationship between the CS and UCS. In the truly random control, there is an equal probability of UCS occurrence in both the presence and the absence of the CS (Rescorla, 1967, 1988b). Experiments designed to examine the effects of a truly random control procedure have found that some conditioning to the CS does occur as a result of fortuitous CS-UCS pairings that occur when there is an equal probability of UCS occurrence in the presence and in the absence of the CS (e.g., Ayers, Benedict, \& Wichter, 1975; Benedict \& Ayers, 1972; Kremer \& Kamin, 1971; but see Rescorla, 1968).

\section{Emergence of a New Response}

Initial experiments using the classical conditioning procedure identified a number of responses (including salivation, leg flexion, finger withdrawal, knee jerk, and eyelid closure) that could be conditioned to a variety of stimuli (see Hilgard \& Marquis, 1940; Hull, 1934). The major 
outcome of these early classical conditioning experiments, as well as many recent experiments, was the emergence of a new response to the CS that in some way resembled the response to the UCS. The emergence of a new response occurred even when the CS elicited a response of its own at the start of conditioning. For example, Pavlov (1927) reported an experiment by Erofeeva in which she presented skin shock as a CS and paired it with a food UCS. Although the CS initially elicited defensive responses, after repeated pairings of shock and food, the dog displayed a conditioned salivary response to skin shock without showing any of the previously observed defensive responses (see Konorski \& Miller, 1937). More recently, Gormezano and Tait (1976) presented groups of rabbits with CS-UCS training trials in which water in the mouth (CS) was paired with air puff to the eye (UCS), or air puff to the eye (CS) was paired with water in the mouth (UCS). Gormezano and Tait (1976) found that, in the former case, rabbits displayed conditioned nictitating membrane extension to water and that, in the latter case, rabbits showed conditioned jaw movement to air puff. Thus, despite unconditioned jaw movement to the water CS and unconditioned nictitating membrane extension to the corneal air puff CS, rabbits were able to acquire a new response to the CS in the effector system elicited by the UCS. Indeed, Gormezano and Tait (1976) reported that acquisition of the new response by animals given paired training reached a level of $90 \%$ CRs, which was substantially and significantly higher than was the level of responses of animals given explicitly unpaired presentations of the CS and UCS.

The emergence of a new response to the CS in the effector system activated by the UCS has historically been used as the index of associative learning (e.g., Hilgard, 1936; Hull, 1934; Lashley, 1916; Pavlov, 1927; cf. Rescorla, 1988b). Moreover, it continues to be advocated as the hallmark of associative learning when classical conditioning procedures are employed (e.g., Gormezano, 1966, 1984; Gormezano \& Kehoe, 1975; Lederhendler, Gart, \& Alkon, 1986). The emergence of a conditioned response that resembles the UCR has led to the postulation that the CS becomes a substitute for the UCS (i.e., stimulus substitution theory, see for example, Hilgard, 1936; Konorski, 1967). Support for the stimulus substitution theory was derived from a number of observations, including Pavlov's (1927) report that a previously conditioned CS could support conditioning when paired with a new CS (i.e., second-order conditioning). However, it soon became clear that many of the responses that emerged as a result of CS-UCS pairings were different from the UCR (e.g., Hilgard, 1936; Zener, 1937). For example, conditioning of pupillary change and heart-rate change produced CRs that were in the opposite direction to those produced by the UCS (i.e., compensatory responses). At a more prosaic level, many CRs differed from UCRs in terms of latency, amplitude, and recruitment (e.g., Hilgard \& Marquis, 1940).

As a result of the lack of identity between a CR and UCR, some researchers abandoned classical condition- ing procedures as the means of studying associative learning. Other researchers have adopted a less stringent specification of conditioned responses and have begun to study behaviors that are related to the CS and/or UCS. These responses have been variously described as instrumental-approach behaviors, sign-directed behaviors, and goal-directed behaviors (e.g., Boakes, 1977; Hearst \& Jenkins, 1974; Holland, 1977, 1980) and are used as evidence that an association has been formed between two events (Dickinson, 1980; Mackintosh, 1983; Rescorla, 1988b). In brief, investigators have proposed that the nature of the conditioned response is determined, in part, by the type of CS and/or UCS employed in any given experiment. For example, in autoshaping (Hearst \& Jenkins, 1974), a pigeon may peck at a keylight with eating or drinking motions, depending on whether food or water has been paired with the lighted key. Holland $(1977,1980)$ has shown that a light may elicit the orienting response of rearing in a rat, whereas a tone may elicit the orienting response of head-turning. The frequency of these behaviors has been shown to change as a function of training (Holland, 1977, 1980). Moreover, Holland (1979) has reported other responses, such as poking the head into a magazine feeder or freezing, that emerge later in the interstimulus interval and appear to be determined by the nature (e.g., food vs. shock) and magnitude (e.g., number of pellets, intensity of shock) of the UCS.

Although the emergence of goal-directed behaviors may be a measure of associative learning (Rescorla, 1988b), the utility of employing such preparations as model systems may be problematic because of the very nature of the responses that are studied. Specifically, the ability to identify the neural substrates of different target responses is hindered by the fact that the responses are recognized in terms of their outcome. That is, an approach response or the depression of a bar or key can occur in any number of different ways that may change from moment to moment, trial to trial, and from animal to animal. The variation in responses and complexity of any single response make it difficult to identify a unique neural output pathway for the target response. Without an identified motor output pathway that is consistent from trial to trial and from animal to animal, it would seem difficult to study the complete neural circuitry and identify the neural substrates involved in these instances of associative learning. However, the isolation of discrete responses or the use of restrained subjects may assist in the identification of potential motor output pathways and thus make preparations that display the emergence of goal-directed behavior a powerful addition to the search for the neural substrates of learning.

\section{MODEL SYSTEMS}

Despite the problems inherent in different definitions of associative learning and differences in what is considered to be a conditioned response, a number of model systems have used classical conditioning procedures to study the neural substrates of associative learning. For 
the purposes of exposition, we shall review a number of model systems that employ classical conditioning procedures to study associative learning and examine these model systems in light of the traditional definition of associative learning.

\section{Aplysia}

Following the successful examination of habituation and sensitization, Carew and Kandel and their colleagues (e.g., Carew et al., 1984; Carew, Hawkins, \& Kandel, 1983; Carew et al., 1981; Hawkins, Carew, \& Kandel, 1986) have sought to develop procedures to demonstrate that the mollusk Aplysia californica is capable of being classically conditioned. In an initial series of experiments reported by Carew et al. (1981), unrestrained, freely moving Aplysia were presented with a CS consisting of a tactile stimulus delivered by a single nylon bristle from a paintbrush held firmly by a hemostat and a UCS consisting of a 1.5-sec pulse of a 50-mA AC electrical stimulus delivered by the manual application of spanning electrodes to the tail. The experimenter applied the CS by inserting the bristle into the funnel of the siphon and briskly moving it upward a single time. The duration of contact with the inner surface of the siphon was estimated to be approximately $0.5 \mathrm{sec}$. Siphon withdrawal was always elicited by both the bristle CS and the electric shock UCS, and, in the former case, the response was measured by a stopwatch.

In a prototypical experiment, Carew et al. (1981) examined the acquisition and extinction of the siphon withdrawal response using six groups: paired CS-UCS, strictly alternating CS and UCS, programmed random $o c-$ currence of CS with respect to UCS, UCS alone, CS alone, and naive. During acquisition, the UCS was presented every $5 \mathrm{~min}$, and, for the paired group, the CS preceded the UCS by $30 \mathrm{sec}$. Siphon withdrawal was tested immediately after the first trial, and then after every five trials. The experimenter conducted extinction by delivering the CS alone for 10 trials immediately after training. Acquisition in the paired group was characterized by a positively accelerated increase in the duration of siphon withdrawal from an initial mean of $8.6 \mathrm{sec}$ to a terminal level of $32.5 \mathrm{sec}$, whereas the control groups did not change significantly during the course of training from their initial durations of $5 \mathrm{sec}$. During extinction, the paired group showed a significant decrease in the duration of siphon withdrawal from Trial 1 (32 sec) to Trial $10(15 \mathrm{sec})$, whereas the control groups showed no systematic change from their initial values of siphon withdrawal (5 sec).

In more recent experiments, Carew et al. (1983) and Hawkins et al. (1986) have attempted to differentially condition the siphon withdrawal response in Aplysia. In a typical experiment (e.g., Carew et al., 1983), subjects were presented with a UCS consisting of tail shock and CSs consisting of nylon bristle stimulation of the siphon and electrical stimulation of the mantle. In two groups of animals, the UCS followed CS+ (siphon or mantle stimu- lation, counterbalanced) by $.5 \mathrm{sec}$ and $\mathrm{CS}-$ (mantle or siphon stimulation, counterbalanced) occurred at the midpoint of the 5-min intertrial interval. The results revealed that, at $15 \mathrm{~min}$ and $24 \mathrm{~h}$ after training, there was a greater increase in the duration of siphon withdrawal to CS + than there was to CS- Hawkins et al. (1986) attributed the increase in siphon withdrawal to CS - to sensitization and the increase in siphon withdrawal to $\mathrm{CS}+$ to associative learning. Examination of the effects of the interval between CS+ and the UCS (interstimulus interval) by Hawkins et al. (1986) revealed that the siphon withdrawal response of greatest duration occurred at an interstimulus interval of $.5 \mathrm{sec}$, with a response of shorter duration at an interval of $1 \mathrm{sec}$ and with little or no increase in duration at longer $(2,5,10 \mathrm{sec})$, shorter $(0 \mathrm{sec})$ or backward $(-.5,-1,-1.5 \mathrm{sec})$ interstimulus intervals.

The Aplysia model system involves a response that occurs to the CS from the outset of training. The response to the CS, siphon withdrawal, is the same as the response to the UCS and thus may be characterized as an alpha response (e.g., Grant, 1944; Kandel \& Spencer, 1968). As a result of a pairings operation, Carew et al. (1981) have observed increases in the duration of the alpha response relative to a number of nonassociative control groups. Interestingly, there are also several vertebrate preparations, including human eyelid conditioning, in which an alpha response is elicited by the CS. In these cases, the characteristics of the alpha response, for example, onset latency and amplitude, are noted, and responses that fall within the latency range of an alpha response are eliminated from consideration as conditioned responses (e.g., Gormezano, 1966; Grant, 1944; Spence \& Ross, 1959). When alpha responses are eliminated from consideration, conditioned responses can be observed to emerge (Grant, 1944) and display characteristic features, such as an onset latency that first occurs at or near the point of UCS onset and then moves forward in time as a function of continued training (e.g., Gormezano, 1966; Martin \& Levey, 1969; Thompson \& Donegan, 1987). To date, there has been no report of the emergence of a new siphon withdrawal response that occurs outside the latency range of the unconditioned siphon withdrawal (alpha) response elicited by the bristle CS.

Because the bristle CS elicits a response quite similar to the siphon withdrawal response elicited by the shock UCS, the Aplysia training procedure may be conceptualized as a procedure in which a weak UCS is followed by a strong UCS. However, in other cases in which two UCSs have been paired, although an unconditioned response to the first UCS has been observed, there has also been a new response that emerges to the first UCS (the "CS') that resembles the UCR to the second UCS (e.g., Gormezano \& Tait, 1976; Konorski \& Miller, 1937; Pavlov, 1927).

The fact that only changes in the Aplysia's alpha response have been reported to date (cf. Lukowiak \& Sahley, 1981) may reflect limitations in the currently employed measurement techniques rather than any inherent 
limitation in the organism's ability to show the emergence of a conditioned response. For example, high-gain mechanical transduction of the siphon withdrawal response (see, for example, use of a force transducer in an in vitro Aplysia gill withdrawal preparation, Lukowiak \& Sahley, 1981) may help resolve small contractions or relaxations of the siphon not detectable by visual inspection. Moreover, mechanical transduction may allow precise specification of response latency, amplitude, and duration providing a number of dependent variables that could be examined for the emergence of a conditioned response (Lukowiak \& Sahley, 1981).

\section{Spinal Cat Preparation}

Patterson, Cegavske, and Thompson (1973) have developed a spinal cat preparation that, like studies with Aplysia, consistently demonstrates changes in an unconditioned response to the CS as a result of CS-UCS pairings (e.g., Beggs, Steinmetz, Romano, \& Patterson, 1983; Patterson, 1975, 1976, 1980). In a typical experiment, cats had their spinal cord transected and the superficial peroneal sensory and deep peroneal motor nerves dissected from the hind limb. The CS consisted of a train of DC current pulses delivered to the sensory nerve, and the UCS consisted of a train of DC current pulses delivered to the ankle skin. In a single session, a paired group first received CS-alone trials, then paired CS-UCS trials, and, finally, CS-alone extinction trials. An unpaired control group received the same number of stimulus presentations, with the exception that the CS-UCS pairings were changed to randomly distributed CS-alone and UCS-alone trials. A CS-alone control group received the same number of CS presentations as did the paired and unpaired groups. The response measure was based on the amplitude of responses to the CS before and after training. The results showed that the response to the CS in the paired group increased rapidly as a function of training and reached a maximum change of $40 \%$ within 10 trials. The unpaired and CS-alone control groups did not show any significant increase in amplitude to the CS and remained at or below initial levels throughout training and extinction. Patterson (1980) has interpreted these results to reflect the unique effects of CS-UCS pairings and, as such, to reflect the operation of associative processes.

Although mindful of the fact that the cat spinal preparation has not demonstrated the emergence of a conditioned response, Patterson $(1976,1980)$ has argued that the spinal cord demonstrates associative learning. As evidence, Patterson (1980) has pointed to the striking resemblance between the amplitude-change functions generated by interstimulus interval studies for the spinal preparation (Patterson, 1975) and the inverted U-shaped CRacquisition function of interstimulus interval studies conducted with intact preparations (e.g., M. C. Smith, Coleman, \& Gormezano, 1969). Beggs et al. (1983) attempted to determine whether the pairing-specific changes in amplitude to the CS were an associative phenomenon by examining extinction and retention of the pairing-specific changes. Beggs et al. (1983) examined the effects of extending the interval between an acquisition and extinction phase so that $.5,1,2,3$, or $4 \mathrm{~h}$ elapsed before extinction was conducted. It was argued that if alpha conditioning were due to sensitization, there should be a gradual decay in the amplitude of the response to the CS simply as a function of time. The results revealed no significant differences among groups subjected to the different acquisition-extinction intervals. Unfortunately, an equivalence in responding among these groups can only result in a failure to reject the null hypothesis and could reflect insufficient statistical power or a large degree of variability in the data. Alternatively, the finding could be explained by the fact that Beggs et al. (1983) failed to employ an interval long enough to contain the sensitization phenomenon (cf. Kandel \& Schwartz, 1982; Pinsker, Hening, Carew, \& Kandel, 1973).

\section{Cat Short-Latency Eyeblink}

Woody and his associates (e.g., Kim, Woody, \& Berthier, 1983; Woody, 1970, 1982, 1984; Woody \& Brozek, 1969; Woody, Knipsel, Crow, \& Black-Cleworth, 1976; Woody, Yarowsky, Owens, Black-Cleworth, \& Crow, 1974) have examined and elucidated changes in the cat's short-latency eyeblink response as a function of pairing a brief click CS with a glabellar tap UCS. In a series of experiments, Woody and his coworkers presented restrained, unanesthetized cats with a minimum of 150 daily training trials consisting of a $1-\mathrm{msec}$ auditory CS (click) followed $400 \mathrm{msec}$ later by a mechanical tap to the glabella. Each of the $\mathbf{1 5 0}$ daily training trials occurred at a fixed intertrial interval of $10 \mathrm{sec}$, and the training trials continued for a period of 15 to 20 days. Control groups consisted of naive animals and animals that received random presentations of the click CS and tap UCS (Woody et al., 1976; Woody et al., 1974). Response measures reported by Woody and his associates included EMG recordings from the obicularis oculi (e.g., Woody \& Brozek, 1969; Woody et al., 1974), recording of neural activity from the area of the facial nucleus (e.g., Woody \& Brozek, 1969), and recording of single- and multiple-unit activity from cortical sensory and motor areas (e.g., Woody, 1970, 1984; Woody \& Black-Cleworth, 1973; Woody et al., 1976).

As a result of repeated pairings of the click and glabella tap, Woody has observed increases in the amplitude of evoked responses in the facial nucleus (e.g., Woody \& Brozek, 1969) and in the sensory and motor cortex (e.g., Woody, 1970). Moreover, Woody et al. (1974) reported an increase in EMG blink-performance levels across 20 training sessions from an initial level of $50 \%$ to a terminal level of $75 \%$ for animals in a paired group and from $30 \%$ to $25 \%$ for animals in a random control group. The high level of initial responding reported by Woody et al. ( $60 \%$ on the first 10 trials) suggests that there is a shortlatency response to the auditory CS from the outset of training (i.e., an alpha response). The existence of shortlatency responses at the beginning of training has been 
observed in a number of other studies of the cat's shortlatency eyeblink, including those of Engel and Woody (1972), Kim et al. (1983), and Woody et al. (1976). Indeed, Woody (1982) has noted that it is the amplitude of the eyeblink response measures that changes as a function of CS-UCS pairings and that the latency of the eyeblink appears to be nearly the same in naive and conditioned animals. Thus, Woody and Brozek (1969) have argued that the short-latency response observed in other preparations, such as the human eyeblink (e.g., Grant, 1943), are actually conditioned responses and that longer latency responses are attributable to operant conditioning. However, it should be noted that short-latency (i.e., alpha) responses reported in human eyelid conditioning can be observed without training (e.g., CS-alone trials), whereas the emergence of the longer latency conditioned responses only occurs as a function of training (e.g., Gormezano, 1966; Grant, 1943; Martin \& Levey, 1969). Moreover, when longer latency responses have been explicitly subjected to instrumental contingencies (e.g., Coleman, 1975), the frequency of responses has decreased rather than increased (Coleman \& Gormezano, 1979). Nevertheless, Woody and Brozek (1969) have asserted that the changes in short-latency EMG activity they observed as a function of CS-UCS pairings were conditioned responses and that there were no other changes in activity during the remainder of the interstimulus interval (Woody, 1982). Interestingly, a preliminary report by Woody et al. (1988) noted significant increases in eyeblink EMG activity throughout the ISI in a procedure in which hypothalamic stimulation followed the click CS and preceded the glabellar tap UCS (Kim et al., 1983). Indeed, Woody et al. (1988) reported that the increases in long-latency EMG activity mirrored increases in short-latency EMG activity. It remains unclear, however, what the role of hypothalamic stimulation may be in these changes (cf. Kim et al., 1983) and whether long-latency changes in EMG activity occur without hypothalamic stimulation.

\section{Hermissenda}

Alkon and his colleagues (e.g., Alkon, 1974, 1980, 1987; Crow \& Alkon, 1978; Farley \& Alkon, 1980; Lederhendler et al., 1986) have studied changes in behavioral responses to light which result from pairings of light and rotation in the mollusk Hermissenda crassicornis. In a typical experiment, Crow and Alkon (1978) presented subjects with 150 acquisition trials (50 trials per day) consisting of $30 \mathrm{sec}$ of a light CS and $30 \mathrm{sec}$ of a rotational UCS. Usually, rotation of the animal elicited clinging, with the body musculature contracted and the foot gripping the bottom of the enclosure (Alkon, 1974; Lederhendler et al., 1986). On the other hand, presentations of the light CS alone to animals placed in the dark during the light portion of their diurnal cycle produced the phototropic response of movement toward the light source. Crow and Alkon (1978) also examined a series of control conditions, including rotation alone, random but separate presentation of light and rotation, light alone, and strictly alternating presentations of light and rotation. The results clearly showed that the paired group had a significantly longer response latency to move toward the light than did any of the control groups.

More recently, Lederhendler et al. (1986) have shown that in addition to a relatively short latency change in displacement in response to light, trained animals also show a new response to light (foot contraction) that emerges as a function of training. Observations of Hermissenda in the dark revealed a shortening of $15 \%$ to $20 \%$ in the length of the foot (the single organ of locomotion) in response to rotation. Lederhendler et al. also noted a small lengthening of the foot in response to light before training. After pairings of light and rotation, Lederhendler et al. (1986) found that the foot contraction, or shortening, elicited as an unconditioned response to rotation emerged as a new response to light in all of the trained animals. The new response of foot contraction to the light did not occur in untrained animals nor did it occur in animals that received random presentations of light and rotation.

\section{Rabbit Nictitating Membrane Response}

Gormezano and his colleagues (e.g., Gormezano, 1966, 1972, 1984; Gormezano, Kehoe, \& Marshall, 1983; Gormezano, Schneiderman, Deaux, \& Fuentes, 1962) have developed and elaborated the rabbit nictitating membrane response (NMR) as a preparation for studying associative learning. The preparation has subsequently been adopted by a number of different research groups as a model system (e.g., Cegavske et al., 1976; Disterhoft, Coulter, \& Alkon, 1986; Moore, 1979; Thompson et al., 1976). Gormezano et al. (1962) first reported classical conditioning of the rabbit NMR using a tone CS and corneal air puff as a UCS. During acquisition training, a paired group showed a progressive increase in CR frequency across days of training to an asymptote of $95 \%$ CRs. In marked contrast, the performance of CS-alone, UCS-alone, and unpaired control groups never exceeded $6 \%$ on any single day and averaged a level not appreciably higher than the base rate of $2 \%$ to $3 \%$. The low rates of responding in the control groups suggested that there was little, if any, evidence of the occurrence of alpha responses, sensitization, or pseudoconditioning.

To specify the empirical laws of the rabbit NMR preparation, Gormezano and his associates have delineated a large number of parameters governing rabbit NMR conditioning. Among the parameters that have been found to affect classical conditioning with simple CS-UCS pairings are CS and UCS intensity, intertrial interval (ITI), and interstimulus interval (ISI). It was found that for both within- and between-subjects manipulations, a more intense CS yields higher levels of conditioning (Gormezano, 1972; Scavio \& Gormezano, 1974). For both air puff and paraorbital electrical stimulation UCSs, increases in intensity have yielded increases in amplitude and frequency of CRs (Gormezano, 1966; M. C. Smith, 1968). However, an inverse relationship has been found to exist be- 
tween overall level of CR acquisition and UCS duration (Tait, Kehoe, \& Gormezano, 1983). In terms of ITI and trials per session, conditioning of the rabbit NMR has been observed to occur more rapidly the longer the ITI and the fewer the number of trials per session (Kehoe \& Gormezano, 1974). Finally, the length of the ISI was found to have a dramatic effect on the strength of conditioning. No conditioning occurred at backward, zero, or forward ISI values equal to or less than 50 msec (e.g., Gormezano, 1972; Smith et al., 1969), but conditioning was moderate at $100 \mathrm{msec}$, maximal at $200-400 \mathrm{msec}$ and began to fall off at $800 \mathrm{msec}$, with little or no conditioning beyond 3,000 msec (Kehoe, 1976; Schneiderman \& Gormezano, 1964).

\section{ASSESSMENT}

It seems clear from a review of the model systems under consideration that Aplysia, the cat spinal preparation, and the cat short-latency eyeblink have demonstrated pairing-specific changes in a preexisting response, whereas Hermissenda and the rabbit NMR have demonstrated the emergence of a new response from among the responses elicited by the UCS. Interestingly, these response differences correspond to the differences between alpha and beta conditioning first suggested by Hull (1934) and subsequently discussed by Kandel and Spencer (1968) and Carew et al. (1984). Specifically, Hull (1934) distinguished between pairing-specific changes in an existing response to the CS, which he described as sensitization, and the emergence of a new response, which he considered to be conditioned responding. However, in keeping with a modern definition of classical conditioning (e.g., Dickinson, 1980), Carew et al. (1984) have suggested that the emergence of a new response is less critical to the study of associative learning than is the knowledge of whether the change in responding to the CS is "specific to pairing" of the CS and UCS (Rescorla, 1988a). Yet the pairing-specific changes observed by Carew et al. (1981), Patterson (1975), and Woody and Brozek (1969) were obtained using a classical conditioning procedure. As we shall see, the traditionally specified classical conditioning procedure makes it possible to observe the emergence of a new response, specify its stimulus antecedents, make an unequivocal statement about the existence of an association, and identify all the elements involved in that association.

In an effort to address the issue of whether or not changes in an alpha response that are brought about by a classical conditioning procedure constitute associative learning, Carew et al. (1984) and Hawkins and Kandel (1984) have argued that there is no fundamental distinction between an alpha response and a conditioned response. Specifically, they point out that, although there may not be a behavioral alpha response in some preparations (e.g., rabbit NMR), there is always a neural alpha response (e.g., rabbit NMR, see Cegavske, Patterson, \& Thompson, 1979). A neural alpha response is said to oc- cur as CS-induced changes in synaptic potential in interneurons or motor neurons (Carew et al., 1984, p. 176). It is argued that a neural alpha response could become a behavioral response through appropriate manipulation (e.g., training or an increase in a parameter, such as CS intensity). Thus, according to Carew et al. (1984), the alpha response and a conditioned response fall on a continuum and, in fact, are fundamentally indistinguishable from each other (Hawkins \& Kandel, 1984). In short, the classical conditioning procedure is claimed to strengthen a neural alpha until it is above threshold and becomes a behavioral response (Hawkins \& Kandel, 1984).

Although a fundamental similarity between conditioned responses and alpha responses is plausible, there are a number of findings (e.g., rabbit NMR) that appear to pose a problem for such an isomorphism. First, the slight elevation in neural activity to CS onset reported by Cegavske et al. (1979) in the rabbit and described as a neural alpha response by Carew et al. (1984) occurred in the abducens nucleus, a structure now known not to form part of the essential motor output pathway of the rabbit NMR (e.g., Berthier \& Moore, 1980; Cegavske, Harrison, \& Torigoe, 1987; Disterhoft, Quinn, Weiss, \& Shipley, 1985; Harvey, Land, \& McMaster, 1984). Second, singleand multiple-unit recordings made in the rabbit's accessory abducens nucleus, the structure now known to contain all the essential motoneurons for the rabbit NMR (e.g., Cegavske et al., 1987; Disterhoft et al., 1985; Harvey et al., 1984), show little, if any, spontaneous activity and no activity at all to an auditory CS (Disterhoft et al., 1985). Third, the neural alpha response in the abducens nucleus of the rabbit (Cegavske et al., 1979) cited by Carew et al. (1984) only occurred in just over half of the animals $(9 / 16)$ that had electrodes in the abducens nucleus. Nevertheless, conditioning of the NMR to a tone and air puff presented under appropriate conditions occurs in almost all rabbits studied (e.g., Gormezano et al., 1983).

In contrast to data from the rabbit NMR that argue against a neural alpha response, data from cat eyeblink experiments may be interpreted as evidence for a neural alpha response. Woody (1982) has argued that neural activity to the CS along a chain of neurons from sensory receptor to muscle end plate is sufficient evidence of a significant response. In fact, as we have noted, Woody and his colleagues (e.g., Woody \& Brozek, 1969; Woody et al., 1976; Woody et al., 1974) have employed shortlatency changes in neural activity to a click CS at sites from sensory cortex to facial nucleus and eyelid muscle as evidence of classical conditioning. However, rather than claim that a neural alpha can become a conditioned response (cf. Carew et al., 1984), Woody (1982) has asserted that the use of a liminal muscle movement as the criterion for a response is arbitrary and that neural activity should replace behavioral data as the measure of associative learning.

Perhaps the most cogent argument against a fundamental similarity between an alpha response and a conditioned response is the fact that even when there is an alpha 
response, a new response has been observed to emerge as a function of training (e.g., human eyelid conditioning). Moreover, there is evidence that the new (i.e., conditioned) response is fundamentally different from pairinginduced changes in the alpha response and that this new response can be distinguished from the pairing-induced changes. For example, over the course of training the frequency of the conditioned response has been shown to increase and the onset of the response (i.e., latency) has been shown to move forward in time, with the peak amplitude of the response occurring at or about UCS onset even when the UCS onset is changed (e.g., Gormezano, 1966; Kehoe, Graham, \& Schreurs, in press; Martin \& Levey, 1969; Millenson, Kehoe, \& Gormezano, 1977; Pavlov, 1927). The dynamic characteristics of the CR (e.g., changes in latency) have not been demonstrated for the alpha response, and the pairing-specific changes that have been reported (e.g., increase in amplitude or duration) may have resulted from the sensitizing effects of the UCS (e.g., Carew et al., 1981; Hawkins et al., 1986; Kim et al., 1983; Patterson, 1975).

As we have noted, Hull (1934) argued that the changes in a preexisiting response to the CS, such as the changes observed in Aplysia, the cat spinal preparation, and cat eyeblink response, may result from the sensitizing or dishabituating effects of the UCS. For example, sensitization did occur to $\mathrm{CS}-$ in the differential conditioning experiments conducted by Hawkins et al. (1986) and Kim et al. (1983). In the Hawkins et al. (1986) study, the observed behavioral changes to CS+ have been suggested to result from pairing-specific sensitization to $\mathrm{CS}+$, a phenomenon distinct from generalized sensitization to CS - (e.g., Gluck \& Thompson, 1987; Hawkins \& Kandel, 1984). As the name suggests, pairing-specific sensitization appears to result from the increased responsivity to the CS brought about by its proximity to the UCS. If the sensitizing effect of the UCS is dependent on the temporal relationship between the CS and UCS, it should reflect alterations in the relationship between the two events. For example, the pairing-specific sensitizing or dishabituating effect of the UCS on the alpha response would be predicted to decrease with increasing intervals between the CS and UCS and would not be expected to occur if the UCS were presented before the CS. In fact, both Hawkins et al., (1986) and Patterson (1980) have reported ISI functions for pairing-specific changes in the alpha response that correspond closely to the results predicted for pairing-specific sensitization (see Gluck \& Thompson, 1987).

In addition to a direct increase in the alpha response brought about by the sensitizing effects of the UCS, pairing-specific changes may be augmented by the ability of the UCS to protect the sensitized alpha response from habituation (e.g., Pfautz, Donegan, \& Wagner, 1978; Rescorla, 1988a; Wagner, 1976; Whitlow, 1975). Such "protection from habituation" (Pfautz et al., 1978) would not occur to CS- or in CS-alone control groups. Thus, differences in the sensitized alpha response to CS+ and CS- or between paired and control groups could result from a decrease in responding to $\mathrm{CS}-$ or to the $\mathrm{CS}$ in the control group rather than from an increase in responding to CS+ or the CS in the paired group. For example, using the behavioral measure employed by Hawkins et al. (1986), namely, the difference between CS+ (posttest minus pretest) and CS- (posttest minus pretest), a decrease in responding to CS- would reflect an overall increase in response duration in the same manner as an increase in CS+. To assess the possibility of protection from habituation afforded by the UCS, a control group would be required that included paired presentations of a CS and a stimulus other than the UCS (Pfautz et al., 1978; Rescorla, 1984).

In light of the foregoing discussion, the question to be answered is whether or not the pairing-specific change in an alpha response brought about by a classical conditioning procedure is an example of associative learning. The answer depends, in large part, on how associative learning is defined when classical conditioning procedures are employed. When the associative learning obtained using classical conditioning procedures is defined in terms of the emergence of a new response, pairing-specific changes in an alpha response are not instances of associative learning. When associative learning is defined as a change in an organism's behavior that results from a classical conditioning procedure, then pairing-specific changes in an alpha response are considered to be instances of associative learning (Rescorla, 1988a).

However, it is only when the emergence of a conditioned response is included in a definition of associative learning that a complete determination of the elements involved in an association can be made (Gormezano, 1984). That is, as a result of the target response being elicited by the UCS from the outset of training (i.e., UCR), the original stimulus antecedent (i.e., the UCS) to that target response (UCR) is known and under experimenter control. The subsequent emergence of a response similar to the target response that results from CS-UCS pairings and not from nonassociative processes can thus be attributed to the occurrence of the CS. As a result, the CS and UCS can be said to have become associated. Moreover, when the stimulus antecedents are known and the target response is specified, classical conditioning becomes an almost ideal procedure for identifying the neural substrates of associative learning; that is, it becomes possible to trace the sensory input pathway for the stimulus antecedent and the motor output pathway for the target response. As a result, the sensory and motor pathways can be examined prior to and independently of the conditioning procedure. Moreover, the formation of a conditioned response can be observed from the outset of training. Finally, identification of the sensory input and motor output pathways provides an opportunity to locate potential convergence sites of the CS and UCS/UCR-sites that may be essential in localizing the neural substrates of learning.

A definition of associative learning that is based on changes in responding to a CS that result from a classical 
conditioning procedure includes pairing-specific changes in an alpha response as examples of associative learning. However, it has been argued that changes in an alpha response that occur as a result of classical conditioning procedures may be the result of pairing-specific sensitization or protection of a sensitized alpha response from habituation. These changes represent a category of behaviors that would be designated pairing-specific nonassociative changes in behavior. Nevertheless, according to a modern definition of associative learning, any change in behavior that is specific to the classical conditioning procedure, including pairing-specific sensitization, protection from habituation, and the emergence of a new response, would be considered an example of associative learning. The inclusion of changes in behavior that result from pairing-specific sensitization and protection from habituation among phenomena defined as associative learning makes a modern definition of associative learning too broad.

\section{CONCLUSION}

The use of model systems to study the neural substrates of learning has highlighted the importance of our understanding of what associative learning is and how it can be assessed. When classical conditioning procedures are employed to demonstrate traditionally defined associative learning, it is possible to specify the stimulus antecedents to the conditioned response and, thereby, to provide a complete determination of the elements involved in an association. The emergence of a new response as a result of CS-UCS pairings is an unequivocal affirmation that an association has been formed.

The use of classical conditioning procedures by researchers interested in uncovering the neural substrates of associative learning increases the likelihood that the sensory inputs, motor outputs, and intervening neural circuitry involved in learning can be identified. Moreover, knowledge of the complete neural circuitry involved in associative learning allows for the determination of sites of CS and UCS convergence and the study of learning's neural correlates.

When departures from the traditionally defined characteristics of classical conditioning occur, the power to study associative learning and its neural substrates is diminished. For example, the examination of changes in an alpha response, although interesting in its own right, does not unequivocally constitute an examination of associative learning. In contrast, the emergence of a new response as a result of CS-UCS pairings taps the full power of the classical conditioning procedure to demonstrate associative learning and pursue the identification of its neural substrates.

\section{REFERENCES}

Alkon, D. L. (1974). Associative training of Hermissenda. Journal of General Physiology, 64, 70-84.

ALKON, D. L. (1976). The economy of photoreceptor function in a primi- tive nervous system. In F. Zettler \& R. Weiller (Eds.), Neural principles of vision (pp. 410-446). Berlin: Springer-Verlag.

ALKON, D. L. (1980). Membrane depolarization accumulates during acquisition of an associative behavioral change. Science, 210, 1375-1376.

ALKON, D. L. (1987). Memory traces in the brain. New York: Cambridge University Press.

Ayers, J. J. B., Benedict, J. O., \&ichter, E. S. (1975). Systematic manipulation of individual events in a truly random control in rats. Joumal of Comparative \& Physiological Psychology, 88, 97-103.

Beggs, A. L., Steinmetz, J. E., Romano, A. G., Patterson, M. M. (1983). Extinction and retention of a classically conditioned flexor nerve response in acute spinal cat. Behavioral Neuroscience, 97, 530-540.

Bekhterev, V. M. (1913). Objektive Psychologie oder psychoreflexologie. Die lehre von den assoziations refflexen. Teubner: Leipzig. BENEDICT, J. O., \& Ayers, J. J. B. (1972). Factors affecting conditioning in the truly random control procedure in the rat. Journal of Comparative \& Physiological Psychology, 78, 323-330.

BerTHIER, N. E., MoORE, J. W. (1980). Role of extraocular muscles in the rabbit (Oryctolagus cuniculus) nictitating membrane response. Physiology \& Behavior, 24, 931-937.

Bonkes, R. A. (1977). Performance on learning to associate a stimulus with positive reinforcement. In $\mathbf{H}$. Davis \& H. M. B. Hurwitz (Eds.), Operant Pavlovian interactions (pp. 67-97). Hillsdale, NJ: Erlbaum.

BRown, T. (1977). Sketch of a system of the philosophy in the human mind. In D. N. Robinson (Ed.), Significant contributions to the history of psychology, 1750-1920 (Vol. 1). Washington, DC: University Publications of America. (Original work published 1820)

BuLLOCK, T. (1948). Properties of a single synapse in the stellate ganglion of squid. Journal of Neurophysiology, 11, 343-346.

Carew, T. J., Abrams, T. W., Hawkins, R. D., \&andel, E. R (1984). The use of simple invertebrate systems to explore psychological issues related to associative learning. In D. L. Alkon \& J. Farley (Eds.), Primary neural substrates of learning and behavioral change (pp. 169-183). New York: Cambridge University Press.

Carew, T. J., Hawkins, R. D., Kandel, E. R. (1983). Differential classical conditioning of a defensive withdrawal reflex in Aplysia. Science, 219, 397-400.

Carew, T. J., Walters, E. T., Kandel, E. R. (1981). Classical conditioning in a simple withdrawal reflex in Aplysia californica. Journal of Neuroscience, 1, 1426-1437.

Castellucci, V. F., \& Kandel, E. R. (1976). Presynaptic facilitation as a mechanism for behavioral sensitization in Aplysia. Science, 194, 1176-1178.

Cegavske, C. F., Harrison, T. A., \& Torigoe, Y. (1987). Identification of the substrates of the unconditioned response in the classically conditioned, rabbit, nictitating-membrane preparation. In I. Gormezano, W. F. Prokasy, \& R. F. Thompson (Eds.), Classical conditioning (3rd ed., pp. 65-91). Hillsdale, NJ: Erlbaum.

Cegavske, C. F., Patterson, M. M., Thompson, R. F. (1979). Neuronal unit activity in the abducens nucleus during classical conditioning of the nictitating membrane response in the rabbit (Oryctolagus cuniculus). Joumal of Comparative \& Physiological Psychology, 93, 595-609.

Cegayske, C. F., Thompson, R. F., Patterson, M. M., GorMEZANO, I. (1976). Mechanisms of efferent neuronal control of the reflex nictitating membrane response in the rabbit. Journal of Comparative \& Physiological Psychology, 90, 411-423.

CoHEN, D. H. (1969). Development of a vertebrate experimental model for cellular neurophysiologic studies in learning. Conditioned Reflex, 4, 61-80.

CoHEN, D. H. (1980). The functional neuroanatomy of a conditioned response. In R. F. Thompson, L. H. Hicks, \& V. B. Shvyrkov (Eds.), Neural mechanisms of goal directed behavior and learning (pp. 283302). New York: Academic Press.

Coleman, S. R. (1975). Consequences of response-contingent change in unconditioned stimulus intensity upon the rabbit (Oryctolagus cuniculus) nictitating membrane response. Journal of Comparative \& Physiological Psychology, 88, 591-595. 
Coleman, S. R., \& Gormezano, I. (1979). Classical conditioning and the "law of effect": Historical and empirical assessment. Behaviorism, 7, 1-33.

Corning, W. C., Dyal, J. A., \& Willows, A. O. D. (1973). Invertebrate learning. New York: Plenum.

Crow, T. J., ALKon, D. L. (1978). Retention of an associative behavioral change in Hermissenda. Science, 201, 1239-1241.

Dickinson, A. (1980). Contemporary animal learning theory. Cambridge: Cambridge University Press.

Disterhoft, J. F., Coulter, D. A., \& Alkon, D. L. (1986). Conditioning-specific membrane changes of rabbit hippocampal neurons measured in vitro. Proceedings of the National Academy of Science USA, 83, 2733-2737.

Disterhoft, J. F., QuinN, K. J., Weiss, C., \& ShIPLEY, M. T. (1985). Accessory abducens nucleus and conditioned eye retraction nictitating membrane extension in rabbit. Journal of Neuroscience, 5 , 941-950.

Ebbinhaus, H. (1913). Memory (H. A. Ruger \& C. Bussenins, Trans.). New York: Columbia University Press. (Original work published 1885)

ENGEL, J., JR., \& WoODY, C. D. (1972). Effects of character and significance of stimulus on unit activity at coronal-pericruciate cortex of cat during performance of conditioned motor responses. Journal of Neurophysiology, 35, 220-229.

FARLEY, J., ALKON, D. L. (1980). Neural organization predicts stimulus specificity for a retained associative behavioral change. Science, 210, 1373-1375.

FLAHERTY, C. F. (1985). Animal learning and cognition. New York: Knopf.

Gabriel, M., Foster, K., Orona, E., Saltwick, S. E., \& StanTON, M. (1980). Neuronal activity of cingulate cortex, anteroventral thalamus in hippocampal formation and discriminative conditioning: Encoding and extraction of the significance of conditioned stimuli. In J. M. Sprague and A. N. Epstein (Eds.), Progress in psychobiology and physiological psychology (Vol. 9, pp. 126-231). New York: Academic Press.

GLuCK, M. A., \& Thompson, R. F. (1987). Modeling the neural substrates of associative learning and memory: A computational approach. Psychological Review, 94, 176-191.

Gormezano, I. (1966). Classical conditioning. In J. B. Sidowski (Ed.), Experimental methods and instrumentation in psychology (pp. 385420). New York: McGraw-Hill.

GoRmezANo, I. (1972). Investigations of defense and reward conditioning in the rabbit. In A. H. Black \& W. F. Prokasy (Eds.), Classical conditioning II: Current research and theory (pp. 151-181). New York: Appleton.

Gormezano, I. (1984). The study of associative learning with CS-CR paradigms. In D. L. Alkon \& J. Farley (Eds.), Primary neural substrates of learning and behavioral change (pp. 5-24). New York: Cambridge University Press

Gormezano, I., \& KeHOE, E. J. (1975). Classical conditioning: Some methodological-conceptual issues. In W. K. Estes (Ed.), Handbook of learning and cognitive processes (Vol. 2, pp. 143-179). Hillsdale, NJ: Erlbaum.

Gormezano, I., \& Kehoe, E. J. (1981). Classical conditioning and the law of contiguity. In P. Harzem \& M. D. Zeiler (Eds.), Predictability, correlation, and contiguity (Vol. 2, pp. 1-45). New York: Wiley.

Gormezano, I., Kehoe, E. J., \& MArshall, B. (1983). Twenty years of classical conditioning research with the rabbit. In J. M. Sprague \& A. N. Epstein (Eds.), Progress in psychobiology and physiological psychology (Vol. 11, pp. 197-275). New York: Academic Press.

Gormezano, I., Schneiderman, N., Deaux, E. G., \& Fuentes, I. (1962). Nictitating membrane: Classical conditioning and extinction in the albino rabbit. Science, 138, 33-34.

Gormezano, I., \& TaIT, R. W. (1976). The Pavolvian analysis of instrumental conditioning. Pavlovian Journal of Biological Sciences, 11, 37-55.

Grant, D. A. (1943). Sensitization and association in eyelid conditioning. Journal of Experimental Psychology, 32, 201-212.

Grant, D. A. (1944). A sensitized eyelid reaction related to the conditioned eyelid response. Journal of Experimental Psychology, 35, 393-404.
Grant, D. A., \& Adams, J. K. (1944). 'Alpha' conditioning in the eyelid. Journal of Experimental Psychology, 34, 136-142.

Harvey, J. A., Land, T., \& McMaster, S. E. (1984). Anatomical study of the rabbit's corneal-VIth nerve reflex: Connections between cornea, trigeminal sensory complex, and the abducens and accessory abducens nuclei. Brain Research, 301, 307-321.

Hawkins, R. D., CAREW, T. J., \& Kandel, E. R. (1986). Effects of interstimulus interval and contingency on classical conditioning of Aplysia siphon-withdrawal reflex. Journal of Neuroscience, 6, 1695-1701.

Hawkins, R. D., \& KANDEL, E. R. (1984). Is there a cell-biological alphabet for simple forms of learning? Psychological Review, 91, 375-391.

Hearst, E., \& Jenkins, H. M. (1974). Sign-tracking: The stimulusreinforcer relation and directed action. Austin, TX: Psychonomic Society.

HiLgaro, E. R. (1936). The nature of the conditioned response: 1 . The case for and against stimulus-substitution. Psychological Review, 43, 366-385.

Hilgard, E. R., Marquis, D. G. (1940). Conditioning and learning. New York: Wiley.

Holland, P. C. (1977). Conditioned stimulus as a determinant of the form of the Pavlovian conditioned response. Joumal of Experimental Psychology: Animal Behavior Processes, 3, 77-104.

Holland, P. C. (1979). The effects of qualitative and quantitative variation in the US on individual components of Pavlovian appetitive conditioned behavior in rats. Animal Learning \& Behavior, 7, 424-432.

Holl.aND, P. C. (1980). Influence of visual conditioned stimulus characteristics on the form of Pavlovian appetitive conditioned responding in rats. Journal of Experimental Psychology: Animal Behavior Processes, 6, 81-97.

HuLl, C. L. (1934). Learning: II. The factor of the conditioned response. In C. Murchison (Ed.), A handbook of general experimental psychology (pp. 382-455). Worcester, MA: Clark University Press.

KANDEL, E. R., \& SCHWARTZ, J. H. (1982). Molecular biology of learning: Modulation of transmitter release. Science, 218, 433-443.

KANDEL, E. R., \& SPENCER, W. A. (1968). Cellular neurophysiological approaches in the study of learning. Physiological Review, 48, 65-124.

KEHOE, E. J. (1976). Effects of serial compound stimuli on stimulus selection in classical conditioning of the rabbit nictitiating membrane response. Unpublished doctoral dissertation, University of Iowa, Iowa City, IA

KeHOE, E. J., \& GoRmeZano, I. (1974). Effects of trials per session on conditioning of the rabbit's nictitating membrane response. Bulletin of the Psychonomic Society, 2, 434-436.

Kehoe, E. J., Graham, P., \& Schreurs, B. G. (in press). Temporal patterning of the rabbit's nictitating membrane response to compound stimuli under mixed CS-US intervals. Behavioral Neuroscience.

Kim, E. H.-J., Woody, C. D., \& Berthier, N. E. (1983). Rapid acquisition of conditioned eye-blink responses in cats following pairing of an auditory CS with a glabellar-tap US and hypothalamic stimulation. Journal of Neurophysiology, 49, 767-779.

KIMBLE, G. A. (1961). Hilgard and Marquis' conditioning and learning. New York: Appleton-Century-Crofts.

KoNORSKI, J. (1967). Integrative activity of the brain: An interdisciplinary approach. Chicago: University of Chicago Press.

KonORSKI, J., \& MILLER, S. (1937). On two types of conditioned reflex. Journal of General Psychology, 16, 264-272.

KREMER, E. F., \& KaMIN, L. J. (1971). The truly random control procedure: Associative or nonassociative effects in rats. Journal of Comparative \& Physiological Psychology, 74, 203-210.

LASHLEY, K. S. (1916). The human salivary reflex and its use in psychology. Psychological Review, 23, 446-464.

LEDERHENDleR, I., GART, S., \& AlKon, D. L. (1986). Classical conditioning of Hermissenda: Origin of a new response. Journal of Neuroscience, 6, 1325-1331.

LUKOWIAK, K. \& SAHLEY, C. (1981). The in vitro classical conditioning of the gill withdrawal reflex of Aplysia californica. Science, 212, 1516-1518.

MACKINTOSH, N. J. (1983). Conditioning and associative learning. Oxford: Oxford University Press. 
Martin, I., \& Levey, A. B. (1969). The genesis of the classical conditioned response. Oxford: Pergamon Press.

Millenson, J. R., Kehoe, E. J., \&ormezano, I. (1977). Classical conditioning of the rabbit's nictitating membrane response under fixed and mixed CS-US intervals. Learning \& Motivation, 8, 351-366.

MoORE, J. W. (1979). Brain processes and conditioning. In A. Dickinson \& R. A. Boakes (Eds.), Mechanisms of learning and motivation: A memorial volume to Jerzy Konorski (pp. 111-142). Hillsdale, NJ: Erlbaum.

Mpitsos, C. J., Colluns, S. D., \& McClellan, A. D. (1978). Learning: A model system for physiological studies. Science, 199, 497-506.

Patterson, M. M. (1975). Effects of forward and backward classical conditioning procedures on a spinal cat hind-limb flexor nerve response. Physiological Psychology, 3, 86-91.

Patterson, M. M. (1976). Mechanisms of classical conditioning and fixation in spinal mammals. In A. H. Riesen \& R. F. Thompson (Eds.), Advances in psychobiology (Vol. 3, pp. 381-346). New York: Wiley.

Patterson, M. M. (1980). Mechanisms of classical conditioning of spinal reflexes. In R. F. Thompson, L. H. Hicks, \& J. B. Shvyrkov (Eds.), Neural mechanisms of goal-directed behavior and learning (pp. 263-272). New York: Academic Press.

Patterson, M. M., Cegavske, C. F., \&hompson, R. F. (1973). Effects of classical conditioning paradigm on hind-limb flexor nerve response in immobilized spinal cats. Journal of Comparative \& Physio logical Psychology, 84, 88-97.

Pavlov, I. P. (1927). Conditioned reflexes: An investigation of the physiological activity of the cerebral cortex (G. V. Anrep, Trans.). London: Oxford University Press.

Pearce, J. M., \& Hall, G. (1980). A model of Pavlovian learning: Variations in the effectiveness of conditioned but not unconditioned stimuli. Psychological Review, 40, 71-89.

Pfautz, P. L., Donegan, N. H., Wagner, A. R. (1978). Sensory preconditioning versus protection from habituation. Journal of Experimental Psychology: Animal Behavior Processes, 4, 286-295.

Pinsker, H. M., Hening, W. A., Carew, T. J., \& Kandel, E. R. (1973). Long-term sensitization of a defensive withdrawal reflex in Aplysia. Science, 182, 1039-1042.

Pinsker, H. M., Kupfermann, V., Castellucci, V., \& Kandel, E. R. (1970). Habituation and dishabituation of the gill-withdrawal reflex in Aplysia. Science, 167, 1740-1742.

Rescorla, R. A. (1967). Pavlovian conditioning and its proper control procedures. Psychological Review, 74, 71-80.

Rescorla, R. A. (1968). Probability of shock in the presence and absence of CS in fear conditioning. Journal of Comparative \& Physiological Psychology, 66, 1-5.

RESCORL.A, R. A. (1978). Some implications of a cognitive perspective on Pavlovian conditioning. In S. H. Hulse, H. Fowler, \& W. K. Honig (Eds.), Cognitive processes in animal behavior (pp. 15-50). Hillsdale, NJ: Erlbaum.

ResCoRla, R. A. (1984). Comments on three Pavlovian paradigms. In J. Farley \& D. L. Alkon (Eds.), Primary neural substrates of learning and behavioral change (pp. 25-45). Cambridge: Cambridge University Press.

Rescorla, R. A. (1988a). Behavioral studies of Pavlovian conditioning. Annual Review of Neuroscience, 11, 329-352.

Rescorla, R. A. (1988b). Pavlovian conditioning: It's not what you think. American Psychologist, 43, 151-160.

Sahley, C., Gelperin, A., \& Rudy, J. W. (1981). One-trial associative learning modifies food odor preferences of a terrestrial mollusc. Proceedings of the National Academy of Science USA, 78, 640-642.

SCAVIo, M. J., JR., \& GormeZANo, I. (1974). CS intensity effects upon rabbit nictitating membrane conditioning, extinction, and generalization. Pavlovian Journal of Biological Sciences, 9, 25-34.

Schneiderman, N., Gormezano, I. (1964). Conditioning of nictitating membrane of the rabbit as a function of CS-US interval. Journal of Comparative \& Physiological Psychology, 57, 188-195.

SKINNER, B. F. (1938). The behavior of organisms: An experimental analysis. New York: Appleton-Century-Crofts.
SMrrh, M. C. (1968). CS-US interval and US intensity in classical conditioning of the rabbit's nictitating membrane response. Journal of Comparative \& Physiological Psychology, 66, 679-687.

Smith, M. C., Coleman, S. R., Gormezano, I. (1969). Classical conditioning of the rabbit's nictitating membrane response at backward, simultaneous, and forward CS-US intervals. Journal of Comparative \& Physiological Psychology, 69, 226-231.

SMith, S., \& GuThRIE, E. R. (1921). General psychology in terms of behavior. New York: Appleton-Century-Crofts.

SPENCE, K. W., \& Ross, L. E. (1959). A methodological study of the form and latency of eyelid response in conditioning. Journal of Experimental Psychology, 58, 376-381.

Tait, R. W., Kehoe, E. J., \& Gormezano, I. (1983). Effects of US duration on classical conditioning of the rabbit's nictitating membrane response. Journal of Experimental Psychology: Animal Behavior Processes, 9, 91-101.

Thompson, R. F., Berger, T. W., Cegayske, C. F., Patterson, M. M., Roemer, R. A., Teyler, T. J., Young, R. A. (1976). The search for the engram. American Scientist, 31, 209-227.

Thompson, R. F., \& DonEgan, N. H. (1987). Learning and memory. In G. Adelman (Ed.), Encyclopedia of neuroscience (Vol. 1, pp. 571574). Boston: Birkhauser.

Wagner, A. R. (1976). Priming in STM: An information-processing mechanism for self-generated or retrieval-generated depression in performance. In T. J. Tighe \& R. N. Leaton (Eds.), Habituation: Perspectives from child development, animal behavior, and neurophysiology (pp. 95-129). Hillsdale, NJ: Erlbaum.

WhitLow, J. W. (1975). Short-term memory in habituation and dishabituation. Journal of Experimental Psychology: Animal Behavior Processes, 1, 189-206.

Wine, J. J., Krasne, F. B., \& Chen, L. (1975). Habituation and inhibition of the crayfish lateral giant fiber escape response. Journal of Experimental Biology, 62, 771-782.

Woony, C. D. (1970). Conditioned eye blink: Gross potential activity at coronal-pericruciate cortex of the cat. Journal of Neurophysiology, 33, 838-850.

Woody, C. D. (1982). Conditioning: Representation of involved neural function. New York: Plenum.

Woony, C. D. (1984). The electrical excitability of nerve cells as an index of learned behavior. In D. L. Alkon \& J. Farley (Eds.), Primary neural substrates of leaming and behavior change (pp. 101-127). New York: Cambridge University Press.

Woody, C. D., Aou, S., Gruen, E., Birt, D., Melamed, O., * Wangwong-Vivat, J. (1988). Short and long latency blink CRs are supported by activity of units in motor cortex and thalamus in cats. Society for Neuroscience Abstract, 344.10.

Woody, C. D., Black-Cleworth, P. (1973). Differences in excitability of cortical neurons as a function of motor projections in conditioned cats. Journal of Neurophysiology, 36, 1104-1116.

Woody, C. D., BrozeK, G. (1969). Changes in evoked responses from facial nucleus of cat with conditioning and extinction of an eye blink. Journal of Neurophysiology, 37, 717-726.

Woody, C. D., Knipsel, J. D., Crow, T. J., Black-Cleworth, P. A. (1976). Activity and excitability to electrical current of cortical auditory receptive neurons of awake cats as affected by stimulus association. Journal of Neurophysiology, 39, 1045-1061.

WOOdY, C. D., YARowSKY, P., OWENS, J., BlaCK-CleWorth, P., * Crow, T. J. (1974). Effects of lesions of cortical motor areas on acquisition of eyeblink in the cat. Journal of Neurophysiology, 37, $385-394$.

ZENER, K. (1937). The significance of behavior accompanying conditioned salivary secretion for theories of the conditioned response. American Journal of Psychology, 50, 384-403.

ZUCKER, R. S. (1972). Crayfish escape behavior and central synapses: II. Physiological mechanisms underlying behavioral habituation. Journal of Neurophysiology, 35, 621-637.

(Manuscript received June 24, 1988;

revision accepted for publication December 5,1988 .) 